\title{
MULTI-LEVEL EDUCATION AND CAPACITY BUILDING FRAMEWORK FOR TECHNOLOGY ADAPTATION
}

Anjana Vyas ${ }^{1}$

\author{
${ }^{1}$ Chair Person, ISPRS TC V/WG 1 \\ ${ }^{1}$ Center for Applied Geomatics, CRDF, CEPT University, Ahmedabad, Gujarat, India.
}

\author{
Commission V, WG 1
}

KEY WORDS: Capacity Building, Multi-Level Education, Geospatial Technology, e-Learning, Capacity Building

\begin{abstract}
:
Advancements in the Geospatial Technology has brought about benefits to various fields in science and technology. The education and the capacity building of geospatial technology plays a very important role within these fields. The current practice of the education is basically dominated by the teacher, huge syllabus, non-relevant knowledge and having very little opportunity for the discussions between the students and teachers. Instead of the unidirectional, monolithic, rigid and traditional teaching in practice, it requires a change to dynamic, evolving, in-process and gradual system of learning to shape the knowledge society. This generates creative, innovative human beings to train them to perform based on the scientific reasoning and empirical evidence in their respective fields. In order to develop, there are three important components: content, practice and cross-cutting to be established as a strategy in the data savvy environment. The 'content' may shift to more emphasis on higher order skills of constructing explanations, the 'practice' would enhance critical thinking as well as synthesis and 'cross-cutting' would synergize the performance expectations. Hence, the modified education and capacity building programmes advocate to move to a competency based model and the imperatives motivate the better use of the technology. This paper explains multiple levels that exists across academic, research and practitioner community that have potential to benefit from geospatial technology and it determines appropriate curriculum, pedagogy and evaluation strategies. It also maps an appropriate framework and approaches for multi-level education and capacity building considering the recent developments in geospatial technology.
\end{abstract}

\section{INTRODUCTION}

Geospatial technology domain has witnessed several disruptions in recent past, from conventional surveying, cartography and photogrammetry approaches to most recent AI powered VR/AR capabilities made available to anyone with a connected device. The geospatial technology being inter-disciplinary in nature is applicable in diverse areas of science and technology including significantly crucial areas such as those of governance, peacekeeping and healthcare sectors (Rawal, Gupta, \& Vyas, 2019) (Convergne \& Snyder, 2015) (Porcasi, et al., 2012). Knowledge Transfer and capacity building in Geographic Information System(GIS) in context of spatial data within Information Systems (IS) in natural resource management like coastal management is very powerful (Stojanovic, Green, \& Lymbery, 2010). Easy accessibility to high-resolution data products, mapping, data management, visualization, navigation, standardization, open source software, open data, internet connectivity, cloud based services has converted an ordinary light-weight device into potential Geospatial technology laboratory. This provides window of opportunity to impart advanced geo-spatial skills to students, researchers and professionals in various academic domains and disciplines of practice. The tapping benefits of advances and developments in the Geospatial technology to all at the fullest requires different types of knowledge and skills that goes well beyond the conventional educational approaches in any single academic discipline. The Indian scenario of student technical training and capacity building through initiatives like Remote Sensing \& GIS Programme by ISRO is very encouraging (Remilla \& Kishore, 2018). Multi-level approach is being implemented across India (Pendyala \& Vijayan, 2018) shown as web based multilevel implementation plan for training using module based learning. Elearning has emerged a successful approach in this regard (Raju, 2012) (Gülch, Al-Ghorani, Quedenfeldt, \& Braun, 2012). Theskills and core competencies are needed to be taken into consideration for curriculum development in many domains in Science and Technology and training be designed accordingly (Pistoria, Dressler, Budnitz, McKean, \& Amin, 2006). This kind of multi-level interventions in training pose some challenges (DiBiase, et al., 2010) (Johnson \& Sullivan, 2010) (Nastasi \& Hitchcock, 2009).

\section{OBJECTIVES}

The aim is to identify multiple levels that exists across academic, research and practitioner community that are or have potential to benefit from Geospatial technology and to determine appropriate curriculum, pedagogy and evaluation strategies for each level.

(a) To identify multiple levels of competency requirements of Geo information theory and practice across diverse disciplines; (b) To study current state-of-the art in standardization of curriculum, pedagogy and evaluation strategy within Geospatial technology field and other pure and applied disciplines; and (c) To design and develop role and level specific recommendations of curriculum, pedagogy and evaluation strategy at multiple levels of competency.

\section{METHODOLOGY}

To attain the proposed objectives of the study, suitable methodology included: (i) Intense Literature review-based identification of parameters and indicators to assessment; (ii) Focus Group Discussion(FGD) and brainstorming meeting; (iii) 
Mapping of appropriate framework for multi-level education and training. This multi-level comprises of academic, researcher and practitioner community relevant to Geospatial technology also to determine: (a) curriculum (b) pedagogy and (c) evaluation.

\section{ANALYTICAL FRAMEWORK}

As mentioned in the methodology, the objectives were to be achieved from the systematic analysis the functional attributes of multiple level target groups. Skills, knowledge, technical expertise are different in different target group and individuals, for example, familiarity of programming languages, algorithms, data management, internet protocols, network protocols, standards, etc. is though gradually becoming essential in many fields may not be necessarily known to every target group. So, as first step towards solving the problem is to identify and characterize all the possible levels of skills and competencies that are required by the students and the researchers that may benefit from technology education and training. Past works have used Knowledge Areas (KA) along with fundamental and core competencies for the training curriculum development in Geospatial technology (Plessis \& Niekerk, 2013) (Plessis \& Niekerk, 2014) whereas, we intend to include individuals nonspecialized in Geospatial technology as well, who belong to different age groups. Education outcome indicators are subject to cognitive, motivational, and socio-cognitive components and depend on cross-curricular competencies (Moskowitz \& Stephens, 2004). As a result, based on criteria:(a) level-ofeducation, (b) technology skills, (c) impact, (d) purpose, (e) resource availability, and (f) familiarity with theory, we classify the target groups as school students, undergrad students, graduate students, researchers, academicians, government, Industry and NGOs as shown in table 1 .

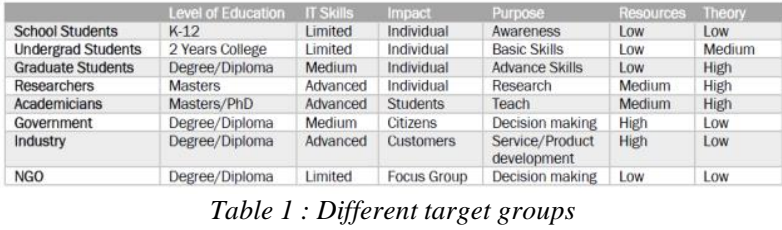

Some level of technology capability is useful right from the school level all the way up to research, industry and practice in various disciplines. While exact determination of competence requirement for each role is an ambitious undertaking, it is certainly possible to characterize the levels at a very coarse level. But generalizing at school level requirement, it can be assumed that individual's level of education may be anywhere between $\mathrm{K}$ 12 , with very limited technology skills, individual impact, the purpose is mainly the awareness, with very low accessibility of resources (like datasets, tools, software, devices) and low familiarity with theoretical concepts. On the other hand, someone with a professional role may have university degree, with advance technology skills, capability to impact large customer base, responsibility for development with accessibility to most advance resources and familiarity with all the theoretical aspects in this domain. Between these two extremes there are possible many other levels as indicated in the table 1 .

Once these levels are identified, the next step is to determine competency needs at different levels. The following table enumerates typical tasks performed in the domain of geomatics along with level of customization or adaptation needed at various levels. For instance, undergraduate level students use available models, tools, generic software packages and basic level processing, interpretation and visualization of data. Whereas on the other extreme, industry professionals may have to define their own data model, collect their own datasets, and apply their preparatory techniques for handling in geospatial technology data in performing their role. Considering these aspects, it is evident that imparting education and training at these levels therefore must take in to account and adopt according to distinguishing characteristics of learners.

The training may have to be imparted at either individual or institutional level whether to academic, commercial, governmental or non-governmental entities while targeting to make learning easier and overcoming barriers through better pedagogical and curriculum development interventions (Ramasubramanian, 1999) (Agboka \& Matveeva, 2018).

\begin{tabular}{|c|c|c|c|c|c|c|c|}
\hline & $\begin{array}{l}\text { UG } \\
\text { Students }\end{array}$ & $\begin{array}{l}P G \\
\text { Students }\end{array}$ & Researchers & Academiclans & Govt & Industry & NGO \\
\hline Generate Data & & & & & Own & Own & Own \\
\hline Acquire Data & Secondary & Secondary & Secondary & Secondary & Own & Own & Own \\
\hline Process Data & & Basic & Advance & Basic & Advance & Advance & Basic \\
\hline Interpret & Basic & Basic & Advance & Advance & Advance & Advance & Basic \\
\hline Compute & Basic & Basic & ce & Basic & Advance & Advance & Basic \\
\hline Model & Use & Use & Develop & Use & & & Use \\
\hline Software Lib & Generic & Generic & Custom & Generic & Custom & Custom & Generic \\
\hline Theory & Use & Use & Develop & Use & Use & Use & Use \\
\hline Visualize & Basic & Basic & Advance & Advance & & Advance & \\
\hline Use Case & Typical & Typical & $\begin{array}{l}\text { Specialized } \\
\text { Yes }\end{array}$ & Typical & Specialized & $\begin{array}{l}\text { Specialized } \\
\text { Yes }\end{array}$ & Specialized \\
\hline $\begin{array}{l}\text { Curation } \\
\text { Dlsseminate }\end{array}$ & & Papers, & $\begin{array}{l}\text { Yes } \\
\text { Papers }\end{array}$ & & $\begin{array}{l}\text { res } \\
\text { Open Gov }\end{array}$ & $\begin{array}{l}\text { Pes } \\
\text { API }\end{array}$ & Reports \\
\hline
\end{tabular}

Table 2: Level of proficiency at each target group

Considering existing and potential beneficiaries of Geospatial capabilities, we have carried out preliminary FDGs and brainstorming sessions as mentioned in second step in methodology with various school students, undergraduate and graduate college students, academicians, researchers, practitioners, consultants, and employees of industry, government and non-governmental organizations. As a result of these sessions, mapping has been done with respect to total skills and core competencies in geospatial engineering as shown in table 3 .

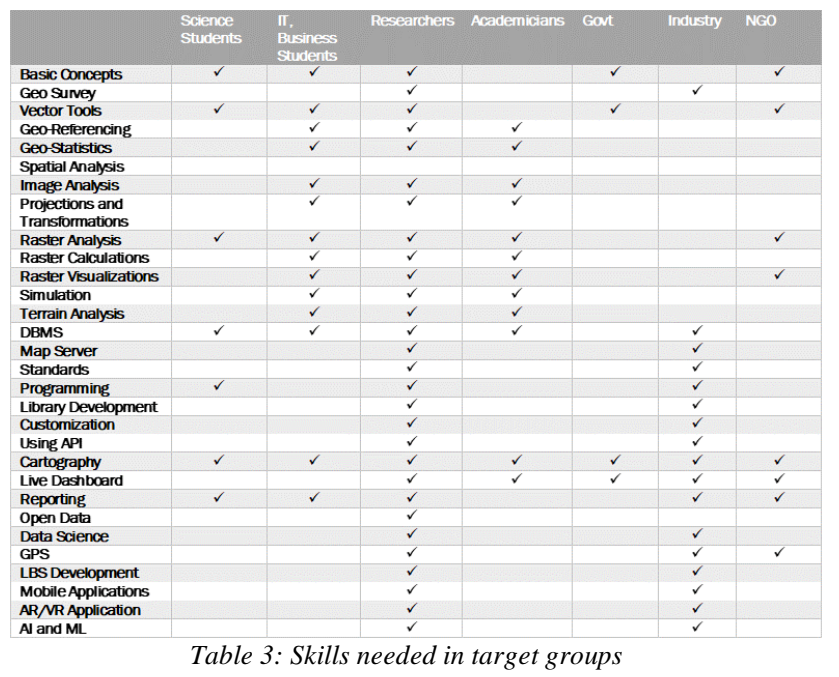

It is obvious that all groups have varying levels of familiarity and accessibility to resources. It is to be observed that an industry professional may have access to all the resources, but may not have a clearly defined education and training program specifically suited for the job on hand. In a different scenario, with free availability of data sets, software packages and selfpaced learning resources, one may have achieved enhanced competencies in Geospatial technology domain. However, it might be difficult for individual to clearly claim the competency due to lack of formal authoritative proof. The need to address these challenges leads to the third step in methodology: outcome of the systematic survey, literature review and experts' interview on all these fronts can be effectively mapped to curriculum, 
pedagogy and evaluation requirements at each level which are the three core pillars of any education program to be effective as shown in figure 1 . This approach of systematic survey followed by design and development of appropriate framework for multilevel education and training tried to cover needs of professionals, students and researchers at various levels in multiple academic disciplines and application domains.
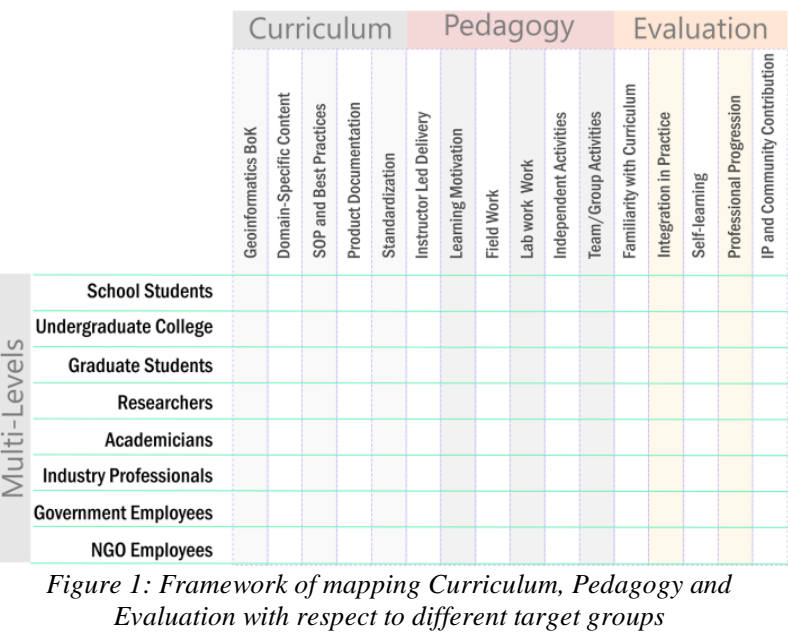

With wide range of practical applicability, data, tools and services in Geospatial technology domain; all three basic pillars must reflect same coverage and agility to maintain relevance. Curriculum includes Geospatial Technology Body of Knowledge (BoK), Domain specific content, Standard Operating Procedures(SOP) and best practices, product documentation and standardization. With wide range of practical applicability, data, tools and services in Geospatial technology domain; all three basic pillars must reflect same coverage and agility to maintain relevance. Curriculum includes Geospatial Technology Body of Knowledge (BoK), Domain specific content, Standard Operating Procedures(SOP) and best practices, product documentation and standardization. The survey investigated uptake of various standard curriculums (NCGIA Core, UCGIS, etc.) and body of knowledge (like GI S\&T USGIS BoK) defined by various organizations. Survey helped identify recommendations and best practices by relevant other organizations in accurately determining the competencies in the domain. Considering the individual stakeholder's requirement of domain-specific knowledge, the proposed framework also proposes ways to connect to domain which is not part of standard geospatial technology curriculum. The systematic survey identifies how various stakeholders are currently building capabilities in formal and informal settings and develop framework that may identify which of the learning resources, tools, datasets, and other resources will be useful at each level. On the curriculum front, relevant topics segments from standard curriculums and body of knowledge be identified right from the school level to advance professionals and for various practitioners. It is imperative to identify relevant learning resources in that specific domain. Similarly, Standard Operating Procedures(SOP), and best practices are specific to different domains, and different communities of practices, and therefore should be linked accordingly. For instance, students, professionals, volunteers working in area of watershed management requires additional familiarity in that domain, which may not be part of core GIS curriculum. Therefore, it is imperative to identify relevant learning resources in that specific domain. Similarly, standard operating procedures, and best practices are specific to different domains, and different communities of practices, and therefore required to be linked accordingly. Users are leveraging specific products and services, and their documentation are also an essential part of the curriculum.

Pedagogical approaches include instructor led delivery, learning motivation, field work, independent activities, team \& other group activities. In addition to surveying the learning resources, attempts have to be made to identify best practices and pedagogical approaches that are published in the form of articles and research papers in key journals, conferences, workshops and symposia in the field of Geospatial technology. Finally, evaluation strategies have to be identified at each level establishing familiarity with curriculum to include integration in practice, self-learning, professional progression, community contributions.

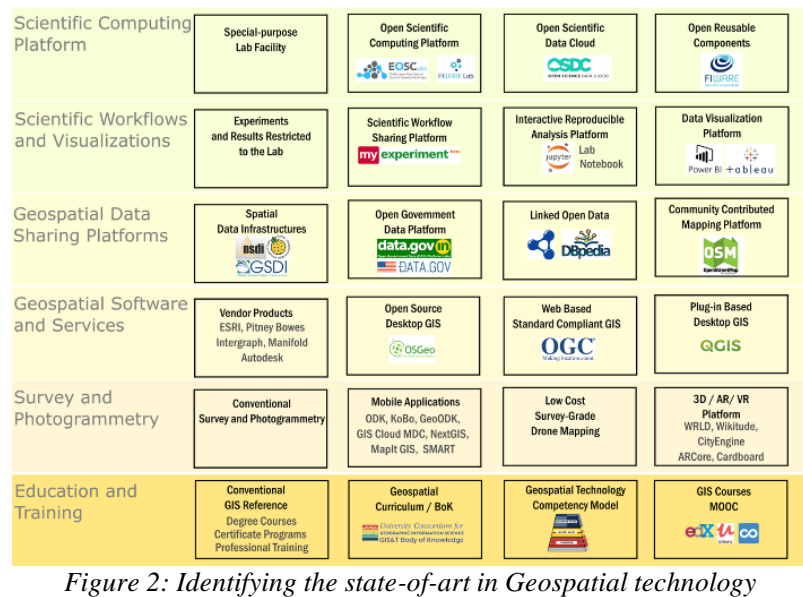

Figure 2: Identifying the state-of-art in Geospatial technology Landscape

Surveying and Photogrammetry is key component in Geospatial technology domain, therefore, state-of-the-art in this aspect determines how current practices have evolved from conventional approaches of specialized equipment to using features offered by mobile applications. This reveals novel approaches, tools, and best practices that can be potentially included in education and training. There are several building blocks which are shown in figure 2. State of-the-art in education and training helps identify how it has evolved from period of conventional textbook oriented instructor lead training to most recent models of self-paced training offered via Massive Online Open Courses. As seen with data, software and visualization capabilities, the sharing of computation power has also evolved over recent times. Open science platform allows anyone to utilize highly capable hardware resources via cloud based access. As with computational capabilities, data storage is also critical component in scientific computing. Open data cloud platform enables shared data storage capability at petabyte scale. Apart from hardware and storage, generic middleware capability is also useful in scientific computing, and equally covered by innovative platforms like FIWARE. Developments on the front of software and services related to handling and analysing geospatial data is another key aspect. Software and services range from proprietary vendor products to free and open source offerings. With large scale adoption of relevant standards and development platforms, it is possible to discover many specialized pluggable components that comes out of specific research project that can be leveraged by integrating them in popular desktop and web based environment.

Availability of spatial data has also increased with adoption to standardization at various levels of data management. Right from encoding, exchange formats to domain specific models, increasing number of data sharing effort not only by agencies 
producing the data products, but also by end-users at different capacities was witnessed. National level spatial data infrastructure programs are established by governmental organizations across the globe. Additionally, with uptake of open data awareness, data from various governmental departments at local, town, municipality, state and central level is now made available. Most countries individually and at union level are now sharing datasets in open formats and also making is accessible via web services. In addition to systematic data sharing programs by governments, there are several large-scale community-driven data curation and sharing efforts that have evolved over time. Linked Open Data cloud in its current form provides machine readable access to large number of datasets, many of which are relevant to users. Projects like Open Street Map offers very robust and reliable access to mapping and navigation capabilities, which is contributed by community. As datasets are critical component of the Geospatial technology domain, it is imperative to determine and include ways to effectively incorporate them in overall education and training strategy.

Taking all the aspects in to consideration, there are few following approaches identified for multi-level target groups:

\begin{tabular}{|c|c|c|}
\hline $\begin{array}{l}\text { Target } \\
\text { Group }\end{array}$ & Subgroups & Approaches \\
\hline \multirow{2}{*}{ Students } & Novices & $\begin{array}{l}\text { Involving novice learners by } \\
\text { popular talks, demonstrations } \\
\text { etc. }\end{array}$ \\
\hline & $\begin{array}{l}\text { Fresh } \\
\text { graduates }\end{array}$ & $\begin{array}{l}\text { Emphasize on enhanced } \\
\text { employability via skill } \\
\text { developments }\end{array}$ \\
\hline \multirow[b]{2}{*}{ Researchers } & Researchers & $\begin{array}{l}\text { Emphasizing on research } \\
\text { collaboration, exchange } \\
\text { opportunities }\end{array}$ \\
\hline & $\begin{array}{l}\text { Knowledge } \\
\text { Workers }\end{array}$ & $\begin{array}{l}\text { Introducing emerging } \\
\text { technologies, trends and } \\
\text { practices preparing future } \\
\text { demands }\end{array}$ \\
\hline \multirow{2}{*}{\multicolumn{2}{|c|}{ Academicians }} & $\begin{array}{l}\text { Assisting them setting up labs, } \\
\text { curriculums and data library }\end{array}$ \\
\hline & & $\begin{array}{l}\text { Hosting regular meet-ups } \\
\text { featuring practitioners, } \\
\text { academician, consultants, } \\
\text { experts etc. }\end{array}$ \\
\hline \multirow{3}{*}{\multicolumn{2}{|c|}{ Industry Professionals }} & $\begin{array}{l}\text { Skill updates program working } \\
\text { with continuous education }\end{array}$ \\
\hline & & $\begin{array}{l}\text { Hosting periodic walk-in } \\
\text { facility to act as quick } \\
\text { assistance/clinic for addressing } \\
\text { challenges }\end{array}$ \\
\hline & & $\begin{array}{l}\text { Hosting email discussion } \\
\text { groups, social media } \\
\text { community pages, to promote } \\
\text { events, exchange of ideas }\end{array}$ \\
\hline \multicolumn{2}{|c|}{ Government and NGOs } & $\begin{array}{l}\text { Emphasize on open source and } \\
\text { open data }\end{array}$ \\
\hline
\end{tabular}

The analytical study resulted in delineation of different target groups, which thereafter brought insights out of curriculum, pedagogy and evaluation based strategies for target groups and finally ended on the note of some recommended interventions which enhance their capabilities in this area.

\section{CONCLUSION}

Aligning with ISPRS mission for the development of international cooperation for the advancement of photogrammetry and remote sensing and their applications, this study results in a framework of multi-level education training in Geospatial technology to address needs of stakeholders at basic, professional and decision-making levels.

The target users for the outcome of this study is grouped in three levels. Conventional users that are familiar with Geospatial technology and have advance infrastructure, tools and capabilities. Second group is early adopters that are mainly on the applied side, leveraging the Geospatial technology in academia, research or practice with intermediate level infrastructure, tools and capabilities. The third group consists of users that are not yet having any kind of specialized infrastructure, resources or capabilities to handle Geospatial technology, but can potentially benefit a lot by developing familiarity. Therefore, the main target users are in this group, and spreading awareness and making Geospatial technology accessible. The paper gives strategies and approaches for multi-level target groups considering three basic pillars: curriculum, pedagogy and evaluation in specific domain of Geospatial technology education.

\section{ACKNOWLEDGEMENTS}

This study has been carried out considering ToR of ISPRS TC V/WG1. Author is thankful to Dr. Vikram Sorathia, Secretary TC V/1 and Mr. Jayachandra Ravi in helping and shaping this paper.

\section{REFERENCES:}

Agboka, G. Y., \& Matveeva, N. (2018). Citizenship and advocacy in technical communication: Scholarly and pedagogical perspectives. Routledge.

Convergne, E., \& Snyder, M. R. (2015). Making maps to make peace: geospatial technology as a tool for UN peacekeeping. International Peacekeeping, 22(5), 565586.

DiBiase, D., Corbin, T., Fox, T., Francica, J., Green, K., Jackson, J., . . . Schuckman, K. (2010). The new geospatial technology competency model: Bringing workforce needs into focus. Journal of the Urban \& Regional Information Systems Association, 22(2).

Gülch, E., Al-Ghorani, N., Quedenfeldt, B., \& Braun, J. (2012). Evaluation and Development of E-Learning Tools and Methods in Digital Photogrammetry and Remote Sensing for Non Experts from Academia and Industry. ISPRS-International Archives of the Photogrammetry, Remote Sensing and Spatial Information Sciences.

Jianya, G., Yue, P., Woldai, T., Tsai, F., Vyas, A., Gruen, H., . . . Musikhin, I. (2017). Geoinformatics education and outreach: looking forward. Geo-spatial information science, 209-217.

Johnson, A. B., \& Sullivan, D. (2010). Geospatial Education at US Community Colleges: Background, Challenges, and Opportunities. Journal of the Urban \& Regional Information Systems Association, 22(2).

Moskowitz, J., \& Stephens, M. (2004). Comparing learning outcomes: International assessment and education policy. Routledge.

Nastasi, B. K., \& Hitchcock, J. (2009). Challenges of evaluating multilevel interventions. American Journal of Community Psychology, 360-376. 
Pendyala, V. G., \& Vijayan, D. (2018). Developing training programs in remote sensing and geospatial applications. ISPRS Annals of the Photogrammetry, Remote Sensing and Spatial Information Sciences, (pp. 4, 1-6.).

Pistoria, M. J., Dressler, D. D., Budnitz, T. L., McKean, S. C., \& Amin, A. N. (2006). How to use the core competencies in hospital medicine: A framework for curriculum development. . Journal of Hospital Medicine.

Plessis, H., \& Niekerk, A. (2013). A Comparison of Geographical Information Science Competency Requirements. South African Journal of Geomatics.

Plessis, H., \& Niekerk, A. (2014). A new GISc framework and competency set for curricula. South African Journal of Geomatics.

Porcasi, X., Rotela, C. H., Introini, M. V., Frutos, N., Lanfri, S., Porcasi, X., . . . Scavuzzo, C. M. (2012). An operative dengue risk stratification system in Argentina based on geospatial technology. Geospatial health, S31-S42.

Raju, P. L. (2012). Satellite based education and training in remote sensing and geo-information: an e-learning approach to meet the growing demands in India. International Archives of the Photogrammetry, Remote Sensing and Spatial Information Sciences, (p. B6).

Ramasubramanian, L. (1999). GIS implementation in developing countries: learning from organisational theory and reflective practice. Transactions in GIS, 3(4), 359-380.

Rawal, D., Gupta, V., \& Vyas, A. (2019). Urban Development Plan Using Open Source Geospatial Technology-A Case Study of Ahmedabad.

Remilla, M., \& Kishore, J. K. (2018). Capacity Building for RS \& GIS Technology Applications: Student Remote Sensing and Geospatial Programme In Academic Institutions. International Archives of the Photogrammetry, Remote Sensing \& Spatial Information Sciences.

Stojanovic, T., Green, D. R., \& Lymbery, G. (2010). Approaches to knowledge sharing and capacity building: The role of local information systems in marine and coastal management. Ocean \& coastal management, 53(12), 805-815. 